\title{
A Sociedade cibernética
}

\section{The cybernetic society}

\author{
Euripedes Falcão Vieira ${ }^{1}$
}

\section{Resumo}

O artigo analisa as mudanças ocorridas na sociedade na transposição de uma época, a modernidade industrial, à outra, a modernidade cibernética. São épocas marcadas por acontecimentos diferenciados no campo da tecnologia, do conhecimento e da informação. Nas duas últimas décadas, particularmente, a mudança em todos os segmentos da sociedade produziu transformações de escala no arcabouço cognitivo, alterando comportamentos e modos de ação e reação ante a nova realidade. Claramente, a nova realidade se impôs e avançou como sociedade cibernética, a sociedade do ciberespaço-tempo com suas narrativas, ainda curtas, dos eventos econômicos, sociais e culturais.

Palavras chaves: Sociedade cibernética; tempo-espaço; cibercultura.

\begin{abstract}
This paper analyzes the changes that have occurred in society during its transition from industrial modernity to the cybernetic modernity. These periods were characterized by different events in the fields of technology, knowledge and information. Changes that occurred in all segments of society in the last two decades have produced significant transformations in the cognitive framework, changing behavior and mechanisms of action and reaction in face of a new reality. Clearly, this new reality has imposed itself and advanced as a cybernetic society, a cyberspace-time society with its still short narratives about economic, social and cultural events.
\end{abstract}

Keywords: industrial modernity; cybernetic modernity; cyberspace-time.

\section{Introdução}

O traço marcante da sociedade contemporânea é a alta tecnologia, introdutora de nova dimensão à comunicação. Não se trata apenas, de uma evolução da realidade física, material, concreta dos objetos, a utilizar os recursos da natureza, mas de uma realidade criada, de impulsos eletrônicos, codificada e simbólica em outra dimensão do tempo-espaço. O físico e o virtual passam a coexistir na cumplicidade e complexidade da configuração cibernética, cujos comandos codificados produzem ondas imateriais. Tem-se, dessa forma, a substituição das pesadas estruturas tecnológicas da modernidade industrial pelas leves, portáteis e ágeis tecnologias eletrônicas, capazes de reduzir distância e tempo aos comandos instantâneos. Penetrando profundamente no cotidiano da vida, as tecnologias eletrônicas criaram o ciberespaço-tempo, pelo qual circulam diariamente grande parte das relações do mundo atual. Não se trata de uma descoberta, mas de uma criação, produto da evolução do conhecimento e da capacidade inventiva humana.

O ciberespaço-tempo é uma concepção tempo-espaço na qual se sucedem movimentos digitalizados em comandos e que representam fatos relacionados à comunicação e à informação. A funcionalidade do ciberespaçotempo é garantida por um sistema de enlaces, interconectando em teias informáticas diferentes pontos de dispersão dos comandos. De outro modo, o ciberespaço-tempo é a configuração tempo-espaço onde se processam as diferentes formas de intercomunicação, em sistema de redes. Há uma base física representada pelos computadores e a digitalização por comandos, e outra virtual configurada na transmissão codificada da informação,

${ }^{1}$ Doutor em Geografia. Professor titular (aposentado) da Fundação Universidade Federal do Rio Grande, Membro Efetivo do Instituto Histórico e Geográfico do Rio Grande do Sul, Participante do Observatório da Realidade Organizacional. Endereço: Rua Cel. Lucas de Oliveira, 2111 apt.701 - Petrópolis - Porto Alegre/RS Brasil - CEP 90460-001. E-mail: euripedesfalcao@terra.com.br.

Artigo recebido em março de 2006 e aceito para publicação em abril de 2006. 
pelas cibervias, e a decodificação para efeito de recebimento das mensagens. Portanto, o ciberespaço-tempo é ao mesmo tempo material e virtual, uma entidade "desterritorializada", para usar a expressão de Lévy (1997, p.51), no sentido de estar em todos os lugares, promovendo e representando a unificação da nova realidade criada pelo avanço tecnológico.

À espacialidade da teia informática se vincula o tempo, pois todos os comandos e as mensagens codificadas e decodificadas que deles se originam têm um tempo de partida e outro de chegada. A rapidez na movimentação dos fluxos digitais garante, praticamente, a instantaneidade das transmissões. O efeito mais sensível é no aniquilamento das distâncias, ou seja, os lugares, por mais separados em pontos espaciais, deixam de ser fatores significantes nas relações a se estabelecerem na dimensão do ciberespaço-tempo. A movimentação nessa configuração tempo-espaço não é representada apenas por fatos produtores das relações econômicas e financeiras. Há uma nova cultura em andamento, uma tecnocultura, ou especificamente, uma cibercultura, tão abrangente nos seus significados e símbolos, capaz de integrar diferentes campos do conhecimento, das artes, da música e da política. É um tempo cultural que se abre a valores universais, repercutindo ao mesmo tempo em diversas partes do mundo. Trata-se, na verdade, de uma relação mais estreita entre a tecnologia e as manifestações culturais. O entendimento da frente cultural que se projeta a partir dos avanços cibernéticos é modelado pelo conhecimento das concepções de tempo-espaço desenvolvidas pela física. Assim, a configuração tempo-espaço se transpõe ao fenômeno da vida e à organização e evolução da sociedade.

\section{Tempo-espaço conhecimento}

O espaço é uma ordem de coexistências e o tempo uma ordem de sucessões, na enunciação, 1715, de Leibniz (1974, p. 413). O espaço é um componente da existência material e o tempo uma seqüência das transformações da matéria. Assim, o espaço e o tempo passam a ser concepções indissociáveis com formas e grandezas derivadas das formas e grandezas da matéria e de suas transformações, movimentos e energia. Pode-se, pois, considerar dois grandes momentos na concepção do espaço e do tempo: a teoria clássica e a teoria da relatividade. Na concepção newtoniana o tempo foi considerado unidade linear independente do espaço; na teoria da relatividade de Einstein, o tempo e o espaço formam uma unidade cósmica indissociável.

A grande ruptura paradigmática na modernidade ocidental, fortemente marcada pela era industrial, foi com a racionalidade científica introduzida a partir do século XVI, cujo momento mais decisivo ocorreu no final do século XVII (1687), quando Newton publica o modelo matemático que estabelece a grande síntese da mecânica celeste. Nela o espaço é uma concepção absoluta e o tempo outra. A nova racionalidade científica que emergiria no início do século XX viria construir outra concepção de espaço e tempo num universo de relatividade, deixando para trás o absolutismo da mecânica celeste. A partir de 1915, com a teoria da relatividade geral de Einstein, o tempo-espaço passou à categoria de unidade cósmica, una, inseparável. Com isso, mudou a geometria do universo, que de tridimensional passou a quadridimensional com a unidade tempo-espaço. Assim, o tempo e o espaço deixam de ser conceituações separadas e independentes para formarem um "objeto quadridimensional chamado espaço-tempo" Hawking (1995, p.40). Como entender a nova concepção do tempoespaço? Qual a natureza do espaço e do tempo? Aristóteles considerava o espaço finito, com um limite para a presença material do universo. Mas se o universo é um cenário de expansão da matéria, carregado de energia primordial a partir do big-bang, pode-se considerá-lo infinito, pois seus limites se expandiriam com o afastamento contínuo dos objetos materiais.

Se a matéria cria e deforma o espaço tem-se que enquanto o universo contiver energia radiante as formas materiais continuarão a dilatar os limites cósmicos, gerando novas morfologias de coexistências e sucessões de estados energéticos e materiais, a dimensionar a natureza do tempo. As duas situações estão indissoluvelmente ligadas, pois a energia radiada poderá representar, por sucessão, uma forma material e, conseqüentemente, uma contagem de eventos que dão forma e natureza ao tempo. Portanto, se a matéria deforma e encurva o espaço é lógico pensar que o tempo também tem forma e igualmente se encurva. A consideração de que o tempo, como unidade independente, "fluía eternamente, independente do que estava acontecendo" Hawking (1995, 42), foi superada pela teoria da relatividade, a partir da qual o espaço-tempo poderia ser entendido como uma unidade 
sujeita às deformações e encurvamentos pela presença da matéria e da energia. A energia deve ser entendida como a "substância da qual são feitas todas as partículas elementares, átomos e, portanto, todas as coisas, e é também aquilo que se move. A energia é uma substância (...) ela pode ser chamada de causa fundamental de toda mudança no mundo" Heisenberg (1999, p.92-93), confirmando Heráclito que afirmara que a energia era a causa fundamental.

A compreensão do tempo-espaço como produto de um universo material, energético e dinâmico, induz à especulação de início e fim para os eventos cósmicos. A singularidade do big-bang é insuficiente para explicar um início, não definido, para a dimensão do espaço e a contagem do tempo e um fim para a possível contração da matéria num único hiper-núcleo, colapsando o espaço e o tempo. Mas ela própria, a singularidade, seria uma forma de tempo-espaço encurvada e dinâmica. Portanto, sem começo e sem fim, a matéria, a energia e o tempoespaço são infinitos nas formas de coexistência e sucessão. A infinidade admitida à configuração de um tempoespaço material-energético e dinâmico elimina qualquer probabilidade de determinismo nos eventos cósmicos. O princípio da incerteza passa a ser dominante, não só em sua enunciação, como admitindo um amplo sistema universal aberto de imprevisibilidade, contrapondo-se a um sistema mecanicista e previsível.

O tanto quanto se pode estabelecer como tempo de eventos são acontecimentos observáveis a partir de um referencial de posição do observador. Contudo, ainda assim, não é possível estabelecer uma medição precisa para a posição e a velocidade de um objeto ao mesmo tempo. A posição e a velocidade do objeto poderão ter outra visão em outro referencial de observação. Na mecânica quântica, "uma partícula não possui uma posição ou velocidade bem definida, mas seu estado pode ser representado pelo que se denomina função de onda. Uma função de onda é um número em cada ponto do espaço que indica a probabilidade de a partícula ser encontrada naquela posição" Hawking (2001, p.106).

O tempo para nós é um signo, uma simbologia para marcar os eventos físicos e sociais. As escalas de tempo do nosso tempo são recorrentes ao movimento da própria Terra e a movimentos dos astros mais próximos, como a Lua, satélite, e a estrela centro do sistema, o Sol. No sistema solar, "a curvatura do tempo-espaço é tão pequena, pelo menos em uma escala macroscópica, que não interfere em nossa idéia habitual de tempo" Hawking (2001, p.106). O nosso tempo, pois, é o tempo como forma das curvaturas e movimento do sistema externo, em primeiro lugar. As civilizações mais antigas assim o entenderam e deram os primeiros passos à elaboração dos calendários. A estabilidade do sistema solar, em escala de longa duração, permite as seqüências temporais de eventos cósmicos próximos sem alterações significativas. Por outro lado, por tratar-se de um sistema periférico ao complexo galáctico, não sofrem influências das profundas e turbulentas transformações na região onde a densidade de matéria é maior e as formas e a escala de tempo se comportam diferentemente da visão antrópica.

A expansão do universo é uma aceitação de realidade científica da atualidade. Ela coloca à reflexão o ponto de origem, o ponto limite da própria expansão e os pontos de retorno. Pelo princípio antrópico, em determinado momento e ponto da observação, olha-se num cone de tempo-espaço que se alarga e fecha na singularidade primordial. Nesse caso os eventos podem mudar de direção, porém o tempo terá sempre um sentido único, o que nos permite estabelecer as noções de passado, presente e futuro. Do ponto de observação à singularidade inicial o tempo flui no reverso, como que curvado para trás: "se seguirmos nosso cone de luz do passado de volta no tempo, ele será curvado para trás pela matéria no início do universo. Todo universo observado está contido em uma região cujo limite cai para zero na posição supostamente inicial (big-bang). Isso seria uma singularidade, um lugar onde a densidade da matéria seria infinita e a relatividade geral clássica deixaria de ser válida" Hawking (2001,41). No sentido contrário, partindo do big-bang, o tempo seguiria o curso de uma curvatura para frente, deixando para trás eventos da expansão, caracterizando o passado, e estabelecendo uma faixa de maior ou menor escala entre dois eventos, o presente, e projetando, na indeterminação, novos eventos, o futuro, numa seqüência infinita. Com a reversão do processo de expansão, por entropia do sistema, o espaço se contrairia e o tempo se encurvaria para trás, no sentido de uma nova singularidade total. A forma e o sentido do tempo seguiriam a forma e o sentido do espaço numa configuração de histórias cósmicas e, portanto, com uma interpretação diferente da que se coloca como eternidade. Uma verdade parece, contudo, bem estabelecida: não há princípio nem fim; o que há é transformação no tempo-espaço onde a matéria, a energia e a vida encenam suas histórias de coexistência e sucessão. 


\section{Tempo-espaço sociedade}

A vida se inscreve na dinâmica dos fenômenos do universo. Não se trata de uma manifestação posterior, mas a revelação de atributos primordiais, compondo o quadro energético de matéria-vida. Nesse sentido, a vida é um fenômeno físico-químico, um sistema de auto-sustentação, cuja base ativa é o princípio das flutuações de energia em sistemas abertos de trocas com os ambientes naturais. Os sistemas vivos se auto-organizam, multiplicam e evoluem. A extrema diversidade de vida no nosso planeta, em ambientes contrastantes, atesta a natureza fenomenológica natural de auto-organização e sustentabilidade de formas existenciais. A existência matéria-viva representa um processo indissociável de relações físico-químicas-ambientais. Por essa razão, a manifestação da matéria-vida não poderá ser concomitante em todos os objetos cósmicos, e também não estar submetida às mesmas formas e metabolismos referenciados ao planeta Terra.

O fenômeno da existência viva na Terra produziu uma biodiversidade mutante e evolutiva ao longo de um tempo cuja escala é representada por signos estabelecidos pelo homem, espécie que se destacou pela racionalidade superior. O tempo natural que é uma ordem de sucessões viu os ambientes terrestres produzirem combinações e relações físico-químicas, auto-organizadas, evolutivas e seqüenciadas da matéria-viva. O tempo social, a ordem de sucessão dos eventos desenvolvidos no avanço da civilização, vem assinalando, em cronologias estabelecidas em signos de tempo, o processo evolutivo da sociedade.

O tempo-espaço da sociedade humana foi construído nos últimos 10.000 anos, uma contagem temporal de pequena escala, considerando a longa duração da vida no planeta. O tempo-espaço no processo evolutivo das civilizações consagra formas sociais e nelas as manifestações cognitivas do sujeito. O conjunto das individualidades forma o coletivo social, princípio de organização da sociedade. Remotamente, a organização social produzia espaços restritos em tempos longos. A cada avanço do impulso civilizador a sociedade se organizava em novas configurações de tempo-espaço. A cada tempo-espaço da civilização humana, como um todo, foram se destacando processos mais rápidos, com maior grau de organização social. A escala de transformação, de evolução nos diversos processos civilizadores que se instalaram, formou uma consciência do tempo para os eventos da vida pessoal e social. Gradativamente, o tempo foi tornando-se "a representação simbólica de uma vasta rede de relações que reúne diversas sequiências de caráter individual, social ou puramente físico" Elias (1998, p.17.). A noção de tempo evoluiria a um domínio crescente na vida social.

A experiência transmitida a cada geração cristaliza um tempo vivido e outro a ser vivido. Um significa passado e outro futuro, ao qual se agregarão novas experiências e novas formas de aprendizado. Vão se delineando na sucessão de experiências e eventos os tempos sociais, em cronologias símbolos que contam a história da sociedade. Na aurora das organizações sociais, sob forte influência dos astros mais próximos, a contagem do tempo seguiu a fenomenologia dos movimentos e posições da Lua em relação ao planeta e da Terra em relação ao Sol. O tempo medido era então o das fases da Lua ou o das estações do ano. A evolução das técnicas, contudo, levaria aos instrumentos de medição cada vez mais precisos, estabelecendo uma sofisticada linguagem de signos representativos do conceito de tempo.

O tempo-espaço social na pós-modernidade ganhou novas significâncias com a rápida evolução das técnicas microeletrônicas. O tempo-espaço cibernético foi produzido por tecnologias evolutivas em realidades antecedentes. Na verdade o mundo real é o mundo da existência viva e nela a espécie humana é produtora permanente de novas realidades. O cibernético é uma realidade que flui pelas cibervias e se concretiza na virtualidade de imagens, signos e símbolos. Ao formar imagens e significados o virtual se torna uma forma de realidade que opera mensagens instantâneas numa extraordinária compressão do tempo-espaço. No mundo cibernético não há mais tempo longo e distância longa, mas o tempo instantâneo e a presença virtual. O tempo virtual coloca na em temporalidade espaços distantes, produzindo efeitos concomitantes aos fluxos econômicos, sociais, políticos e culturais.

A realidade virtual, um "verdadeiro oxímoro" Baudrillard (2001, p.42), tem, na verdade a duplicidade do sentido, agregando à percepção concreta, material, a realidade do imaterial, a virtualidade do que não pode ser tocado, mas pode ser sensibilizado por meio de signos. Para Thiry-Cherques (2004, p.226-227) "signo é uma uni- 
dade que compreende a união do significante (imagem) com o significado (conceito); no signo, o elo entre o significante e o significado é arbitrário". Por ser arbitrário pode ser elevado à condição simbólica de uma realidade. O tempo-espaço da realidade virtual, como produção das novas tecnologias, é um horizonte que irá se ampliar sem limites nas próximas décadas. A vida social estará condicionada ao uso cada vez mais intensivo do tempo-espaço virtual, tanto no plano da individualidade como da coletividade. O conhecimento e a informação passam rapidamente para o plano das tecnologias virtuais, com a instantaneidade e as simbologias que introduzem um novo mundo às percepções do cotidiano. O tempo da ação e o espaço onde ela se opera é uma realidade dissociada do concreto, do conhecido pela percepção direta, onde os fluxos de desejos circulam por vias não identificáveis materialmente, mas tão verdadeiras pelos efeitos que produzem e pela carga de signos e significados que traduzem.

A nova concepção de tempo-espaço nas organizações é outra realidade da pós-modernidade. O tempo das estratégias no mundo dos negócios se desenrolava independente do local da ação. As estruturas organizacionais, muitas vezes distantes espacialmente, recebiam estratégias de ação a serem desenvolvidas, elaboradas em tempos e espaços dissociados. O tempo tinha uma consideração própria e, também, o espaço. Na verdade, a sociedade estava dominada pelas concepções compartimentadas de tempo e espaço. Predominou por mais de dois séculos o paradigma do tempo absoluto e do espaço absoluto da mecânica newtoniana, mesmo após a introdução da relatividade geral de Einstein e com ela da unidade tempo-espaço. A teoria que provocaria a grande ruptura epistemológica foi se confirmando pela experimentação e observação científica, porém na prática social e econômica só com a evolução tecnológica é que a unidade tempo-espaço começou a construir a nova realidade.

Nas três últimas décadas do século XX o desenvolvimento da microeletrônica ofereceu às atividades econômicas, particularmente, a possibilidade de ação conjunta do tempo-espaço e com ela a instantaneidade da informação e a presença da simbologia virtual. Nas atividades econômicas os novos signos, códigos e significados do tempo-espaço cibernético possibilitaram profundas transformações nas estratégias de ação em escala planetária. A economia global é acima de tudo uma convergência de fluxos de demandas e fluxos decisórios na compressão do tempo-espaço, sem fronteiras e em sistema integrado de redes. O tempo-espaço cibernético construído pela alta tecnologia é subjetivo, virtual e imaterial, mas, ao mesmo tempo, torna-se real pela objetivação das condutas.

A presente atualidade é o cenário da sociedade em transformação. Há uma transição a ser considerada entre a modernidade que chega ao fim e a outra que se introduz pelos aparatos da tecnologia, da mudança de mentalidade e pelo ideário global. Como bem assinalou Santos (2001, p.41), "Há um desassossego no ar. Temos a sensação de estar na orla do tempo, entre um presente quase a terminar e um futuro que ainda não nasceu (...) Não é o calendário que nos empurra para a orla do tempo, e sim a desorientação dos mapas cognitivos, interaccionais e societais em que até agora temos confiado (...) Vivemos, pois, numa sociedade intervalar, uma sociedade de transição paradigmática". O tempo-espaço da transição já consumiu uma década, 1990-2000, e, certamente, projetar-se-á ainda pela próxima década em diferentes durações. As culturas mundiais têm tempos diferentes não só à consolidação de suas tradições como às mudanças de costumes. Contudo, de alguma forma, todas participam das realidades da nova modernidade, embora, para não tão poucas há um atavismo, um endemismo cultural difícil de ser ultrapassado.

A mudança no mundo das organizações é atualmente uma função da variável tempo-espaço no mundo cibernético. Mudança que vem provocando um enorme impacto nos nossos mapas mentais, pois não raramente temos que vivenciar a nova realidade, com seus signos e significados, com uma linguagem ainda impregnada de signos e significados da modernidade antecedente. A compatibilidade do novo tempo-espaço, e do aparato tecnológico que o embasa, com outras formas de expressão verbal é uma transição pontuada que dificulta, muitas vezes, o entendimento da época que se introduz e da mudança que a identifica.

No âmbito das organizações, públicas, particularmente, o grande confronto gerado pelo avanço das tecnologias da informação foi entre o tempo-espaço cibernético e o tempo-espaço da burocracia. As estruturas organizacionais no serviço público brasileiro, particularmente, caracterizam-se pelo excesso de órgãos, pela hierarquização vertical e pelo acentuado estancamento funcional. $\mathrm{O}$ formato piramidal dos serviços multiplica a funcionalidade 
do sistema, gerando normas e ações corporativas. O sistema funcional torna-se pesado, de baixa energia para os fluxos de demandas e ações decisórias, incorporando e consagrando um tempo-espaço lento de pouca eficiência. Esse cenário contrasta com a rapidez, funcionalidade, horizontalidade e eficácia do tempo-espaço cibernético. No confronto, a transição torna-se conflituosa e demorada, produzindo a dissociação com o tempo de atualização. Portanto, para os setores mais dinâmicos da sociedade o tempo-espaço define a nova atualidade, tornase vanguarda, enquanto que para as organizações públicas o tempo-espaço é perenidade, tornando-se retaguarda.

O tempo-espaço pode representar duas dimensões na ordem social: o tempo-espaço dos fluxos que movimentam a informação, os capitais, as demandas e as decisões, promovendo a interação organizacional no modelo cibernético; e o tempo-espaço dos lugares, a realidade tangível das ações humanas, no mundo concreto e físico onde espaço é lugar e tempo é sucessão. Essas dimensões balizam o cotidiano da presente atualidade numa duplicidade e cumplicidade modeladoras das novas formas de organização da vida social. O corpo social incorporou a realidade do tempo-espaço cibernético, projetando para o futuro um envolvimento cada vez mais amplo. As tecnologias a emergir nas próximas décadas tornarão mais sensíveis as relações entre o sujeito e o objeto, o que poderá afetar mais profundamente as percepções da nova realidade em processo de construção.

Mas há uma tomada de consciência a ser considerada para realidades sociais onde a desigualdade é a forma mais contundente da ordem social: a nova concepção de tempo-espaço, no uso de tecnologias avançadas, se de um lado amplia o horizonte de reflexão de parte da sociedade, por outro distancia ainda mais, na vida prática, as diferenças econômicas, sociais e culturais. Entre as realidades brasileiras, a oculta e a explícita, essa é uma verdade indiscutível. A oculta, das práticas ilícitas se expressa perfeitamente na afirmação de Touraine (1999, p.367), "não há democracia onde reinam o dinheiro, o clientelismo, o espírito cortesão, as gangues ou a corrupção". A realidade explícita, a da ordem social, mostra, insofismavelmente, as desigualdades, e nelas toda dramaticidade da pobreza e das manifestações primarias de cultura.

A ruptura epistemológica na concepção de tempo e espaço ocorrida no campo da física e que se refletiu na ordem social, instrumentalizada pelas tecnologias mais avançadas no mundo da microeletrônica, abriu novas perspectivas à organização da sociedade, aos comportamentos individuais e coletivos e aos novos parâmetros culturais. Não é prudente estabelecer marcos à dinâmica do tempo-espaço para os próximos futuros. Mas certamente ela será mais ativa e produzirá novas formas operacionais à sociedade. Talvez o que melhor definirá o processo de transformação da sociedade nas próximas décadas será uma permanente evolução, sem transição, uma sucessão contínua de tecnologias, comportamentos e modos de vida, numa palavra, de tempo-espaço sempre novo.

\section{Presença da cibercultura}

Se a cibernética já é uma força dominante na condição social da presente atualidade, a configurar um estado de época, é natural que se possa falar em cibervias e cibercultura entre outros neologismos derivados do avanço informático-tecnológico. Cada época tem seus signos acompanhados de estruturas lingüísticas correspondentes. Vale lembrar Bakhtin (1995, p.43), quando afirma que "cada época e cada grupo social têm seu repertório de formas de discurso na comunicação sócio-ideológica... a realidade da palavra é absorvida por sua função de signo", assegura o autor. O grande signo da presente modernidade é a cibernética, acompanhada de novas formas de linguagem e de manifestações socioculturais. É uma onda que se propaga em movimentos crescentes na dimensão ciberespaço-tempo, ampliando-o como construção de uma nova realidade em evolução permanente. A ciência e a tecnologia são portais à construção de novos conhecimentos e de novas técnicas que provocam rupturas epistemológicas em relação às estruturas cognitivas formadas e ativadas por signos de épocas. A maneira de pensar, julgar e os valores estabelecidos durante a modernidade industrial sofreram uma brusca ruptura epistemológica a partir do momento da introdução de novo signo. Com efeito, o computador, e o computador pessoal, particularmente, e com ele, a construção do ciberespaço-tempo e mais ainda do sistema de intercomunicação - as redes ou teias - provocaram a grande ruptura epistemológica representativa do modelo de racionalidade dominante até os anos 70 do século XX. 
Os eventos sociais que se desenrolaram durante o longo período da revolução industrial foram desencadeados em contexto de evolução dos conhecimentos científicos, do aprimoramento de novas tecnologias e do sistema de produção. A época, dominada pela industrialização de grande porte e sua predominância no processo de acumulação de capital e, ainda, diferenciador de classes sociais, construiu uma base epistemológica sólida de saber conceitual. Nela, se inseriu o conhecimento científico relacionado a fenômenos naturais e os que deram origem à ordem social estabelecida. É possível capturar o ambiente epistemológico da época a partir dos pressupostos estabelecidos para o funcionamento do sistema universo e o do sistema social. Esses sistemas, a mecânica clássica de Isaac Newton e a economia política clássica de David Ricardo e Adam Smith formaram as bases epistemológicas da época moderna.

A configuração cognitiva apoiada no paradigma da verdade absoluta, na religião, na economia, na política, na ciência e na filosofia conduziu à forte moldura dogmática da ordem cultural. O dogmatismo impôs uma lógica de pensamento e aceitação à totalidade social, embora, com menos ressonância e mais restrita ao cotidiano, se mantivesse um consenso utilitário da vida para as camadas culturalmente dimensionadas em outra escala. Santos (2002, p.40-41), fala do senso comum como modo das classes subordinadas viverem sua subordinação, salientando que nas "subculturas" há sentidos de resistência à ordem social da qual estão afastadas e, como exemplo, oferece suas experiências investigativas nas favelas do Rio de Janeiro (1974-1980).

O rompimento com a ordem cultural da modernidade industrial viria, inicialmente, com uma ruptura epistemológica no campo da ciência. Com efeito, a teoria da relatividade de Einstein produziu a ruptura no conhecimento teórico da concepção do universo e suas forças atuantes. Pouco mais tarde, o paradigma revolucionário (1917) colocaria a resistência das classes subordinadas como uma insubordinação e ascensão criando um tempo de conflito social, econômico, tecnológico e cultural que dominou a maior parte do século XX. Contudo a chama que incendiou a ordem cultural do liberalismo apagou-se prematuramente. Talvez seja permissível, para melhor retratar a insubordinação revolucionária, recorrer-se novamente a Santos (2002, p. 39); "uma vez feita a ruptura epistemológica, o acto epistemológico mais importante é a ruptura com a ruptura epistemológica". A configuração epistemológica do movimento revolucionário de esquerda representou uma ação políticoideológica de ascensão dos subordinados à nova dimensão cultural. Talvez se possa especular sobre uma possível nebulosidade cognitiva responsável, surpreendentemente, pela rapidez da ruptura com a ruptura em 1989 (queda do modelo revolucionário), abrindo caminho à ordem cultural que desde os anos 70 já vinha pedindo passagem.

Toda modernidade representa mudança e inovação desencadeadas por um signo referencial. A máquina a vapor e o computador são signos de modernidades que produziram rupturas na evolução da sociedade. Por pósmodernidade se entende a transposição de uma época à outra. Em cenários futuros, outras pós-modernidades serão introduzidas ao tempo de novas modernidades tecnológicas, científicas e de informação. Assim caminham as modernidades, suas mudanças e rupturas. Os dogmas culturais cedem à flexibilização das imagens e símbolos de uma realidade que se impõe pelas inovações tecnológicas, pela instantaneidade das comunicações e informações. A cultura da nova modernidade é transitiva, irradiando-se pelo ciberespaço-tempo com novas formas lingüísticas, estéticas e padrões cognitivos. A cibercultura aproxima-se demasiado da racionalidade instrumental, o que, de certa forma, a caracteriza como um domínio de competências voltadas aos poderes globais, transterritoriais e mercantilistas. Desta forma, a cibercultura torna-se uma manifestação desterritorializada dos costumes, do conhecimento e das artes.

A cibercultura, para Lévy (1997, p.51) é "o conjunto das técnicas (materiais e intelectuais), as práticas, as atitudes, as maneiras de pensar e os valores que se desenvolvem conjuntamente com o crescimento do ciberespaço". Essa configuração cognitiva tem uma universalidade própria, na dimensão da transterritorialidade dos poderes, das manifestações do saber e da cultura. A cibercultura é, pois, uma forma de movimento social no ciberespaço-tempo, cuja extensão está permanentemente na fronteira do conhecimento. À medida que se desenvolvem novas tecnologias e técnicas no âmbito da cibernética, mais se ampliam ações sociais no universo multilateral da cultura. Há uma interação entre as diversas manifestações de cultura que transitam pelo ciberespaço-tempo, porém há formas, com expressões lingüísticas próprias, que são produtos da própria tecnologia das comunicações e da informação. Os neologismos introduzidos representam de certa forma, a substrução hermenêutica da 
nova modernidade. A linguagem é diferenciada e as palavras introduzidas trazem outros significados e a extensão do mundo da nova realidade.

Mudanças e rupturas culturais inundam o cenário da vida; as técnicas informáticas permitem uma interconexão mais ampla e sempre atual com a inovação, os costumes, os gostos artísticos, musicais e as informações sobre a política, os movimentos sociais e o conhecimento científico. Mesmo nos níveis sociais inferiores o uso das técnicas cibernéticas começa a exercer influência cultural. Em locais de extrema pobreza, como nas áreas faveladas, iniciativas de organizações de várias dependências jurídicas instalam infra-estruturas de treinamento e formação técnica, o que permite uma nova modalidade de integração social no âmbito da cibercultura. No mundo da desigualdade social emergem formas de interação sócio-cultural por meio da cibercultura. Essa, pois, não é discriminatória como outras formas de manifestação cultural. Se há lixo cibercultural esse atinge a sociedade como um todo; se há conquistas, igualmente, todos se beneficiam. Não há fronteiras sociais que não estejam abertas às manifestações e aos movimentos da cibercultura. Até poucas décadas, e em grande parte ainda é assim, o melhor da cultura era unicamente um privilégio das classes mais favorecidas. O pior, por sua vez, era absorvido pelos níveis sociais mais baixos, mesmo porque estavam distantes da formação média e superior. A cibercultura não só muda como provoca uma ruptura no modelo cultural pela interação das técnicas. $\mathrm{O}$ aperfeiçoamento das técnicas e a qualificação das mensagens, certamente, trarão grandes benefícios à interação, inicialmente, e, posteriormente, à integração social no universo dos desníveis educacionais e culturais. Esse será o caminho à inteligência coletiva que os autores ligados a cibercultura têm referenciado. São na verdade práticas de ativação no campo da cultura, abrangente à totalidade comunitária.

As desigualdades sociais são fundamentalmente desigualdades culturais, seja considerando a cultura na formação literária, seja na formação técnica ou artística. O nível cultural depende do processo educacional, até onde ele capaz de atingir as coletividades e permitir o fenômeno da mobilidade social. A educação como processo integra diferentes níveis de escolaridade que permitem a ascensão cultural e com ela a elevação do padrão de vida. Refiro-me, aqui, não à cultura no sentido antropológico ligado à noção de identidade, mas sim no sentido de conhecimento. Não há, pois, instrumento de política pública mais eficaz para diminuir as desigualdades culturais do que a educação. Vieira e Vieira (2004, p.177) afirmam que "não há melhor projeto para a recuperação do atraso cultural, para o resgate da pobreza histórica e para a qualificação do sujeito nacional do que o centrado na educação, na pesquisa e no desenvolvimento cultural; e acrescentam: cada país será resultado de seus investimentos em educação".

A cibercultura é um meio e complemento à difusão do conhecimento e da informação. Não se sobrepõe às formas e manifestações culturais espontâneas, programação de eventos ou processos contínuos de educação e formação. Contudo, a cibercultura (técnica e dos negócios) terá um domínio cada vez mais abrangente na vida individual e coletiva. $\mathrm{O}$ conhecimento e a informação, fontes de cultura, estarão presentes nos meios eletrônicos com crescente intensidade, praticamente impossível de serem desconsiderados. Como instrumento complementar, não substitui as formas impressas e orais de cultura, mas, não há dúvida, que tende a exercer um fascínio e um culto muito além da simples curiosidade que marcou sua ascendência. Considerá-la um instrumento de dominação das elites virtuais, do capitalismo virtual ou para os mais radicais do liberalismo virtual é desconsiderar a capacidade individual e coletiva de identificar o que possa representar descendência cultural do que possa ser identificado como corpo de conhecimentos capaz de erigir um pensamento não referencial, de percepção e lógica independente e de sólida construção intelectual.

Com ou sem a utilização do ciberespaço-tempo, sempre haverá influências dos meios de divulgação do conhecimento e da informação, dependendo como e com que interesses são disponibilizados e da competência cognitiva de absorção por parte do sujeito, individual e coletivo. Não há, portanto, e essa é a nova realidade explícita, fundamento dialético de negação da cibercultura, pois, trata-se, de fenômeno técnico expandido ao mundo dos negócios e ao universo sociocultural, representativo de uma época que se instala sob os auspícios da utopia tecnológica. 


\section{Considerações finais}

A sociedade do ciberespaço-tempo é uma realidade da nova época; um tempo de horizontes fugidios, envolventes e inexoráveis. Nela, tempo-espaço torna-se uma variável determinante às estratégias que encenam diariamente o espetáculo dos eventos econômicos, sociais e culturais. A cibercultura é uma manifestação eloqüente da dimensão cultural estabelecida pela interconexão dos comandos portadores de mensagens e da imagem simbólica da nova sociedade.

A sociedade cibernética será uma sociedade de permanente mudança pela própria condição tecnológica que lhe dá sustentação. Nada mais permanecerá por muito tempo no mesmo lugar. Tanto no plano individual, social, como na ordem econômica global. Os poderes transterritoriais serão mais transcendentes aos poderes nacionais, o que leva à percepção de soberanias compartilhadas e, naturalmente, a determinadas rupturas de identidades.

Em pouco mais de um decênio a sociedade transmudou-se rapidamente, pressionada pelas inundações do conhecimento e da informação. Um tempo de conflito certamente, e previsivelmente, se instalou, confrontando a nova realidade com a realidade em fase de esgotamento; uma impondo-se como realidade do presente para o futuro; a outra, mantendo-se encastelada em ambientes de conservadorismo.

Os modelos cognitivos dominantes, o mapeamento mental de grande parte dos atores sociais sofreu o rápido ataque dos paradigmas e dos símbolos da sociedade que se instala. Essa constatação envolve graves problemas de ordem psicológica à medida, de acordo com a formação de cada sujeito envolvido, das manifestações de sentimentos de rejeição ou aceitação. A rejeição individual quase sempre permanece no mundo interior, do cognoscitivo pessoal, no plano dos sentimentos, percepções e avaliações da realidade. Contudo, a ação prática, na inserção da ordem social, produz uma conduta que não pode fugir à dimensão sociológica; a contradição acaba por gerar conflito de individualidade.

A sociedade cibernética, pós-moderna, é uma transposição de época, assinalada por um signo determinante de profundas transformações na ordem econômica, social e cultural. Os paradigmas da pós-modernidade irão dominar por um tempo de transição entre uma realidade que se apaga à outra que emerge triunfante. O futuro será dominado por avanços mais rápidos e eloqüentes no mundo da tecnologia, do conhecimento e da informação. Nada mais será tão duradouro como em modernidades passadas. A sociedade sempre se adaptará à inundação de mudanças e inovações! 


\section{Referências}

BAKTHTIN, Mikhail. Marxismo e filosofia da linguagem. São Paulo: Hucitec, 1995.

BAUDRILLARD, Jean. Senhas. Rio de Janeiro: Difel, 2001.

ELIAS, Norberto. Sobre o tempo. Rio de Janeiro: Jorge Zahar Editor, 1998.

HAWKING, Stephen. Buracos negros, universos-bebês e outros ensaios. Rio de Janeiro: Rocco, 1995.

O universo numa casca de noz. São Paulo: Mandarim, 2001.

HEISENBBERG, Werner. Física e filosofia. Brasilia: Humanidades/UnB, 1999.

LEIBNIZ, Gottfried W. Correspondência com Clarke. Coleção "Os Pensadores". São Paulo, 1974.

LÉVY, Pierre. Cibercultura. Lisboa: Instituto Piaget, 1997.

SANTOS, Boaventura de Souza. Crítica da razão indolente: contra o desperdício da experiência. São Paulo: Cortez Editora, 2001. Introdução a uma ciência da pós-modernidade. Porto: Edições Afrontamento, 2002.

THIRY-CHERQUES, Hermano Roberto. Estrutura e condição: argumentos em favor dos métodos estruturalistas em pesquisas no campo das ciências de gestão. Revista de Administração Pública (RAP), Rio de Janeiro: Escola Brasileira de Administração Pública e de Empresas da FGV (EBAPE/FGV), v. 38, n. 2, 2004, p. 226.227.

TOURAINE, Alan. Crítica da Modernidade. Rio de Janeiro: Vozes, 1999.

VIEIRA, Euripedes Falcão e VIEIRA, Marcelo Milano Falcão. A dialética da pós-modernidade. Rio de Janeiro: FGV Editora, 2004 